\title{
Effect of the Implantable Atrial Defibrillator on the Natural History of Atrial Fibrillation
}

\author{
HUNG-FAT TSE, M.B.B.S., CHU-PAK LAU, M.D., CHEUK-MAN YU, M.B.B.S., \\ KATHY L.F. LEE, M.B.B.S., GREGORY F. MICHAUD, M.D.,* \\ BRADLEY P. KNIGHT, M.D.,* FRED MORADY, M.D.,* \\ and S. ADAM STRICKBERGER, M.D.*
}

From the Division of Cardiology, Department of Medicine, University of Hong Kong, Queen Mary Hospital, Hong Kong, China; and the *Division of Cardiology, University of Michigan Medical Center, Ann Arbor, Michigan

Implantable Atrial Defibrillator. Introduction: The purpose of our study was to evaluate the effect of repeated cardioversion with an implantable atrial defibrillator on the clinical outcome of patients with atrial fibrillation.

Methods and Results: The effects of the implantable atrial defibrillator on the total duration of atrial fibrillation, number of atrial fibrillation recurrences, and left atrial size were evaluated prospectively in 16 patients with atrial fibrillation ( 13 men and 3 women; mean age $58 \pm 11$ years). Seven patients had no cardiovascular disease, 5 patients had hypertension, 3 patients had coronary heart disease, and 1 patient had congenital heart disease. Eight patients had paroxysmal atrial fibrillation for a mean duration of $80 \pm 61$ months, and eight patients had persistent atrial fibrillation for a mean duration of $68 \pm 119$ months. Except for one patient who received digoxin throughout the study, all patients received the same Class I or III antiarrhythmic agent throughout the study. The implantable atrial defibrillator successfully converted 50 (93\%) of 54 spontaneous episodes of atrial fibrillation in 12 patients. During the initial 3 months of clinical follow-up, the atrial defibrillator documented $261 \pm 270$ hours of atrial fibrillation compared with $126 \pm 172$ hours $(P=0.01)$ during the subsequent 3 months. The left atrial size decreased from $4.4 \pm 0.7 \mathrm{~cm}$ at the time of atrial defibrillator implantation to $4.1 \pm 0.6 \mathrm{~cm}(\mathrm{P}=0.02) 6$ months later. The number of atrial fibrillation recurrences did not change. These findings were observed in the absence of changes in drug therapy. No complications were observed.

Conclusion: Restoration and maintenance of sinus rhythm in patients with atrial fibrillation by repeated cardioversion with an implantable atrial defibrillator was associated with a reduction in the total arrhythmia duration and a reduction in left atrial size. These results suggest that maintenance of sinus rhythm with the atrial defibrillator may reverse the remodeling process associated with atrial fibrillation. (J Cardiovasc Electrophysiol, Vol. 10, pp. 1200-1209, September 1999)

cardioversion, supraventricular arrhythmia, atrial fibrillation

\section{Introduction}

Recent studies in animals and humans suggest that atrial fibrillation alters the electrophysiologic properties of the atrium and facilitates the

Address for correspondence: S. Adam Strickberger, M.D., Division of Cardiology, University of Michigan Medical Center, $1500 \mathrm{E}$. Medical Center Drive, Room B1-F245, Ann Arbor, MI 48109 0022. Fax: 734-936-7026.

Manuscript received 15 March 1999; Accepted for publication 31 May 1999. maintenance and recurrence of atrial fibrillation. ${ }^{1,2}$ If the electrophysiologic changes associated with atrial fibrillation can be prevented with early cardioversion, the likelihood of recurrent atrial fibrillation and its sequelae may be reduced. The implantable atrial defibrillator is an effective device for the early detection and cardioversion of atrial fibrillation. . $^{3-5}$ The purpose of this study was to evaluate prospectively the effect of implantable atrial defibrillator therapy on the natural history of atrial fibrillation. 
TABLE 1

Clinical Characteristics of Implantable Atrial Defibrillator Recipients

\begin{tabular}{|c|c|c|c|c|c|c|c|c|c|}
\hline $\begin{array}{l}\text { Patient No./ } \\
\text { Gender }\end{array}$ & $\begin{array}{c}\text { Age } \\
\text { (years) }\end{array}$ & $\begin{array}{c}\text { Heart } \\
\text { Disease }\end{array}$ & LVEF & $\begin{array}{l}\text { LA Size } \\
\quad(\mathrm{cm})\end{array}$ & $\begin{array}{c}\text { AF } \\
\text { Duration } \\
\text { (months) }\end{array}$ & $\begin{array}{c}\text { Type of } \\
\text { AF }\end{array}$ & $\begin{array}{c}\text { Previous } \\
\text { Electrical } \\
\text { Cardioversion }\end{array}$ & $\begin{array}{c}\text { Previous Drugs } \\
\text { Used }\end{array}$ & $\begin{array}{c}\text { Drugs at } \\
\text { Implantation } \\
\text { and Follow-Up }\end{array}$ \\
\hline $1 / \mathrm{M}$ & 69 & None & 0.54 & 4.1 & 156 & Paroxysmal & 2 & A, Dig, P, Q, S & A, W \\
\hline $2 / \mathrm{F}$ & 62 & HT & 0.6 & 4.7 & 120 & Paroxysmal & 2 & $\mathrm{~A}, \mathrm{D}, \mathrm{P}, \mathrm{Q}, \mathrm{S}$ & A, W \\
\hline $3 / \mathrm{M}$ & 64 & None & 0.61 & 4.4 & 48 & Paroxysmal & 0 & A, Dig, P, Q, S & A \\
\hline $4 / \mathrm{M}$ & 50 & CHD & 0.6 & 4.6 & 24 & Persistent & 3 & A, Dig, P, S & $\mathrm{A}, \mathrm{W}$ \\
\hline $5 / \mathrm{M}$ & 32 & None & 0.6 & 3.5 & 168 & Paroxysmal & 0 & A, Dig, Fl, P, Q, S & $\mathrm{Fl}, \mathrm{BB}$ \\
\hline $6 / \mathrm{M}$ & 68 & None & 0.58 & 3.4 & 70 & Paroxysmal & 0 & BB, Dig, P, S & S, ASA \\
\hline $7 / \mathrm{M}$ & 61 & HT & 0.33 & 6.0 & 29 & Persistent & 2 & A, Dig, D & A, W \\
\hline $8 / \mathrm{F}$ & 60 & HT & 0.53 & 4.4 & 21 & Persistent & 1 & $\mathrm{~A}, \mathrm{BB}, \mathrm{D}, \mathrm{S}$ & A, W \\
\hline 9/M & 70 & None & 0.6 & 4.9 & 48 & Persistent & 2 & Dig, P, S & $\mathrm{A}, \mathrm{W}$ \\
\hline $10 / \mathrm{M}$ & 57 & HT & 0.65 & 3.6 & 6 & Persistent & 1 & $\mathrm{~S}, \mathrm{P}$ & S, W \\
\hline $11 / \mathrm{M}$ & 50 & None & 0.6 & 3.9 & 18 & Paroxysmal & 0 & $\mathrm{Fl}, \mathrm{S}$ & $\mathrm{Fl}, \mathrm{BB}, \mathrm{ASA}$ \\
\hline $12 / \mathrm{M}$ & 65 & HT & 0.55 & 4.6 & 48 & Paroxysmal & 0 & A, BB, Dig, P, Q & $\mathrm{A}, \mathrm{W}$ \\
\hline $13 / \mathrm{F}$ & 66 & CAD & 0.45 & 4.3 & 9 & Paroxysmal & 1 & $\mathrm{~A}, \mathrm{~S}, \mathrm{BB}$ & Dig \\
\hline $14 / \mathrm{M}$ & 55 & CAD & 0.55 & 4.3 & 360 & Persistent & 2 & A, Dig, BB & $A, W$ \\
\hline $15 / \mathrm{M}$ & 41 & None & 0.63 & 4.3 & 48 & Persistent & 1 & A, BB, Dig & A, W \\
\hline $16 / \mathrm{M}$ & 55 & CAD & 0.45 & 6.0 & 4 & Persistent & 1 & $\mathrm{~A}, \mathrm{BB}, \mathrm{S}$ & A, W \\
\hline
\end{tabular}

$\overline{\mathrm{A}}=$ amiodarone; $\mathrm{AF}=$ atrial fibrillation; $\mathrm{ASA}=$ aspirin; $\mathrm{BB}=$ beta blocker; $\mathrm{CAD}=$ coronary artery disease; $\mathrm{CHD}=$ congenital heart disease; $\mathrm{Dig}=$ digoxin $\mathrm{D}=$ diltiazem; $\mathrm{F}=$ female $\mathrm{Fl}=$ flecainide $\mathrm{HT}=$ hypertension; $\mathrm{LA}=$ left atrium; $\mathrm{LVEF}=$ left ventricular ejection fraction; $\mathrm{M}=$ male; $\mathrm{P}=$ propafenone; $\mathrm{Q}=$ quinidine; $\mathrm{S}=$ sotalol; $\mathrm{W}=$ warfarin.

\section{Methods}

\section{Patient Population}

The study population consisted of 13 men and 3 women (mean age $58 \pm 11$ years) who were treated with an implantable atrial defibrillator for symptomatic, drug-refractory atrial fibrillation (Table 1). Seven patients had no cardiovascular disease, 5 patients had hypertension, 3 patients had coronary heart disease, and 1 patient had congenital heart disease. Each patient had recurrences of atrial fibrillation despite treatment with at least one Class I or III antiarrhythmic drug. During episodes of atrial fibrillation, 2 patients noted dizziness, 11 noted palpitations, 5 noted shortness of breath, 6 noted chest pain, and 11 noted weakness.

Prior to implantation of the atrial defibrillator, atrial fibrillation terminated spontaneously within 48 hours of onset in eight patients with paroxysmal atrial fibrillation. Atrial fibrillation recurred at least 2 weeks after successful external or internal cardioversion and persisted indefinitely and for at least the 1 month prior to device implantation in eight patients with persistent atrial fibrillation. The patients had paroxysmal atrial fibrillation for $80 \pm 61$ months (range 18 to 168). The eight patients had persistent atrial fibrillation for a mean duration of $68 \pm 119$ months, and the most recent episode had persisted for $3.9 \pm 1.9$ months (range 1 to 8 ). There were no identifiable differences between patients with paroxysmal and persistent atrial fibrillation (Table 2).

After a detailed medical history and physical examination, all patients underwent a preprocedure evaluation consisting of a 12-lead ECG, 24-hour Holter monitoring, chest radiograph, transthoracic and transesophageal echocardiog-

TABLE 2

Clinical Characteristics and Echocardiographic Results

\begin{tabular}{lccc}
\hline & $\begin{array}{c}\text { Paroxysmal Atrial Fibrillation } \\
(\mathbf{n = 8})\end{array}$ & $\begin{array}{c}\text { Persistent Atrial Fibrillation } \\
(\mathbf{n = 8})\end{array}$ & P Value \\
\hline Age (years) & $60 \pm 13$ & $56 \pm 6$ & 0.5 \\
Male/Female & $6: 2$ & $7: 1$ & 1.0 \\
Duration of atrial fibrillation (months) & $80 \pm 61$ & $68 \pm 119$ & 0.4 \\
Structural heart disease (\%) & $2(25 \%)$ & $5(63 \%)$ & 0.3 \\
Left ventricular ejection fraction & $0.57 \pm 0.05$ & $0.54 \pm 0.10$ & 0.3 \\
Left atrial diameter (cm) & $4.1 \pm 0.5$ & $4.8 \pm 0.8$ & 0.03 \\
\hline
\end{tabular}

Values are given as mean \pm SD. 
A
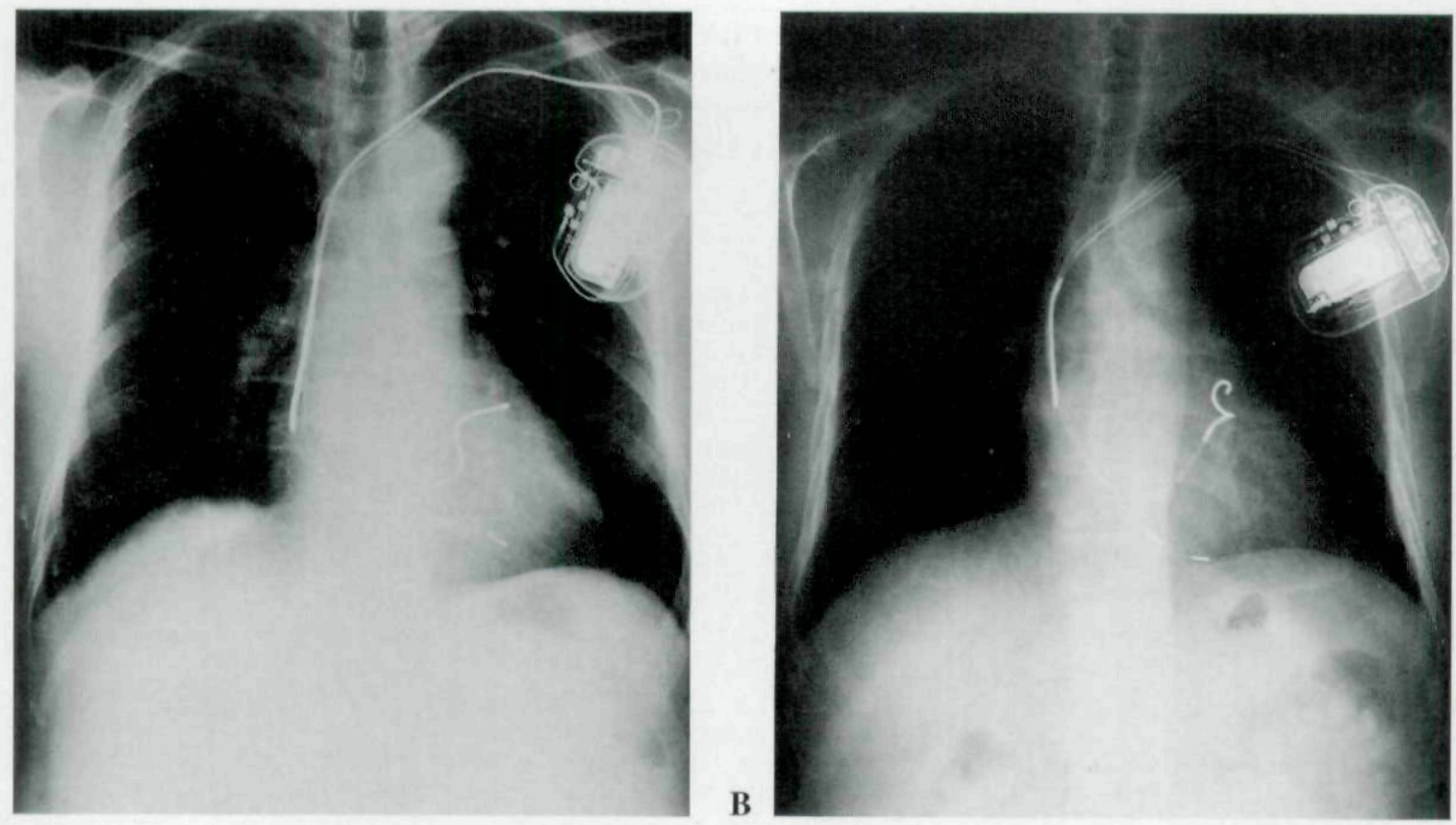

Figure 1. Posteroanterior chest radiograph of a patient with a two-lead (A) and a three-lead (B) implantable atrial defibrillator system. (A) The lead with two defibrillation coils was positioned in the right atrium and distal coronary sinus. (B) An active fixation lead with a single defibrillation coil was positioned in the right atrium and a passive fixation lead with a single defibrillation coil was positioned in the coronary sinus. Both systems utilized a standard bipolar pacing lead for ventricular sensing and pacing.

raphy, serum electrolyte measurements, complete blood court, and thyroid function tests. Patients with any of the following conditions were excluded from study participation: (1) reversible causes of atrial fibrillation, such as electrolyte imbalance or hyperthyroidism; (2) clinically significant valvular heart disease or the presence of a cardiac valve prosthesis; (3) unstable angina or a myocardial infarction within the previous 6 months; (4) New York Heart Association Class III or IV heart failure during sinus rhythm; (5) echocardiographic evidence of left atrial thrombi; or (6) coexisting ventricular tachyarrhythmias.

\section{Implantable Atrial Defibrillator System}

The ethics committee or institutional review board at both participating centers approved the protocol. Written informed consent was obtained from each patient. A previously described implantable atrial defibrillator (models 3000 or 3020, Guidant, St. Paul, MN, USA) was used in conjunction with either a one- or two-lead defibrillation system. ${ }^{3-5}$ Both lead systems were positioned under fluoroscopic guidance from the cephalic and/or subclavian vein. In three patients, a single passive fixation defibrillation lead was positioned in the coronary sinus (Fig. 1A). This lead had a distal defibrillation coil that was positioned in the coronary sinus and a proximal defibrillation coil that was positioned in the right atrium (Guidant model 7309). In 13 patients, a dual lead system was utilized (Fig. 1B). An active fixation lead with a single defibrillation coil (Guidant model 7205) was positioned in the right atrium. The second passive fixation lead that was positioned in the coronary sinus also had a single defibrillation coil (Guidant model 7109). A standard bipolar endocardial ventricular pacing lead was used for $\mathrm{R}$ wave synchronization and ventricular pacing with each of the defibrillation lead systems.

The implantable atrial defibrillator performed atrial sensing and defibrillation between the right atrial and coronary sinus coil electrodes. The intracardiac atrial and ventricular electrograms were used in specific algorithms for atrial fibrillation detection and $\mathrm{R}$ wave synchronization. ${ }^{5}$ The device stored the atrial and ventricular intracardiac electrograms from the six most recently identified episodes of atrial fibrillation. The 
stored data included how the device synchronized to the ventricular electrogram, the date and time of the onset of episodes of atrial fibrillation, and the duration of the 170 most recently detected atrial fibrillation episodes. Shocks were synchronized to the ventricular electrogram and were only delivered after an RR interval of at least $500 \mathrm{msec}$. VVI pacing was a programmable feature.

Although the implantable atrial defibrillator had three programmable therapy modes, only the monitor mode was used when patients were outside the hospital. The device was programmed to sense every 120 minutes. When the sensing sequence was initiated, atrial electrogram sensing and $\mathrm{R}$ wave synchronization were performed. The sensing interval required approximately 2 minutes to complete, then the cycle was repeated. In the monitor mode, the device stored episode data, but did not deliver shocks. Patients were instructed to come to the hospital or clinic for each episode of symptomatic atrial fibrillation. Under physician supervision, the device was programmed to the automatic mode, and a shock was automatically delivered. Sedation with intravenous midazolam was administered at the request of the patient. Success or failure of each shock was noted. Early reinitiation of atrial fibrillation was defined as the recurrence of atrial fibrillation within 1 minute of a successful cardioversion. ${ }^{4}$ The implantable atrial defibrillator delivered a biphasic shock with a leading- and trailing-edge duration of either 3 or $6 \mathrm{msec}$, with a maximum output of $300 \mathrm{~V}$ (Guidant models 3000 and 3020).

\section{Atrial Defibrillation Threshold Testing}

The atrial defibrillation threshold was determined using an up-down defibrillation protocol starting at $180 \mathrm{~V}$ after adequate sedation was achieved with intravenous fentanyl and/or midazolam. ${ }^{4}$ Implantation of the device required successful conversion of atrial fibrillation to sinus rhythm with at least 1 of 3 attempts using either $260 \mathrm{~V}$ (Guidant model 3000) or $240 \mathrm{~V}$ (Guidant model 3020). Atrial defibrillation threshold testing was repeated using the same protocol 1 and 3 months after device implantation. When patients were in sinus rhythm, atrial fibrillation was induced with a low-intensity shock synchronized to the $\mathrm{R}$ wave or with rapid atrial pacing through a temporary catheter.

\section{Implantable Atrial Defibrillator Episode Log}

The device's episode log was used to identify the duration of each episode of atrial fibrillation with an accuracy of \pm 2 hours. An episode of atrial fibrillation identified during only one sensing interval was defined as persisting for 2 hours, but actually may have persisted from 1 minute to 3 hours 59 minutes. The longest single episode of atrial fibrillation that could be recorded with this device was 340 hours. If 170 consecutive sensing intervals demonstrated atrial fibrillation, then the episode was defined as lasting 340 hours. However, this observation could have been due to paroxysmal episodes of atrial fibrillation that were present during each sensing interval. Additionally, in this instance, the episode may have persisted beyond 340 hours.

\section{Follow-Up}

An investigator evaluated each patient 1, 3, and 6 months after the implantable atrial defibrillator was implanted. During these outpatient visits, the device was interrogated to determine the number and total duration of atrial fibrillation episodes. A surface echocardiogram was performed during the 6-month follow-up visit to evaluate the left atrial diameter and left ventricular ejection fraction. Left atrial size from the baseline and follow-up surface echocardiograms was estimated from the parasternal long-axis view. The measurement was determined independently by two echocardiographers in a subset of 11 patients. The measurements obtained from each echocardiogram were within $1 \mathrm{~mm}$ in each case. From the time of atrial defibrillator implantation and throughout the study period, the goal was to avoid altering antiarrhythmic drug therapy, if possible. Aspirin or warfarin was prescribed at the discretion of the investigator (Table 1).

Antiarrhythmic medication remained unchanged throughout the study period (Table 1). However, the dosage was adjusted in six patients who were receiving amiodarone. The dosage of amiodarone was reduced in one patient who developed symptomatic bradycardia and in two patients in whom spontaneous episodes of atrial fibrillation could not be converted with $300 \mathrm{~V}$. In the remaining three patients, the dosage of amiodarone was temporarily increased for 2 weeks because of two or more symptomatic episodes of atrial fibrillation per week. After atrial defibril- 
lator implantation, 12 patients were treated with warfarin and 2 patients were treated with aspirin (Table 1).

\section{Statistical Analysis}

Continuous variables are expressed as mean \pm $1 \mathrm{SD}$ and were compared using a $t$-test or an analysis of variance, as appropriate. Discrete variables were compared using a Chi-square test. A prospective decision was made to evaluate the data from all patients and to stratify the data according to the diagnosis of persistent or paroxysmal atrial fibrillation. Additionally, a prospective decision was made to compare the number of episodes of atrial fibrillation and total duration of atrial fibrillation that occurred during the first 3 months and second 3 months after the atrial defibrillator was implanted. $\mathrm{P}<0.05$ was considered statistically significant.

\section{Results}

\section{Treatment of Spontaneous Episodes of Atrial Fibrillation}

During the 6-month follow-up, 12 patients $(75 \%)$ received implantable atrial defibrillator therapy for at least one spontaneous episode of atrial fibrillation, and 4 patients did not receive implantable atrial defibrillator therapy for a spontaneous episode of atrial fibrillation. In 1 of the 4 patients who did not receive a shock from the implantable atrial defibrillator for a spontaneous episode of atrial fibrillation, atrial fibrillation did not recur after the implantable atrial defibrillator was implanted for the treatment of persistent atrial fibrillation. The remaining three patients who had a history of paroxysmal atrial fibrillation developed symptomatic atrial fibrillation, but they did not come to the hospital for cardioversion by the implantable atrial defibrillator.

The 12 patients who received implantable atrial defibrillator therapy had 54 episodes of spontaneous atrial fibrillation for which a shock from the device was delivered $(4.5 \pm 4.1$ episodes per patient; range 1 to 14). Seventeen of these episodes $(31 \%)$ occurred in five patients with paroxysmal atrial fibrillation. The remaining 37 episodes (69\%) occurred in seven patients with persistent atrial fibrillation. A total of 136 shocks were delivered for the treatment of these
54 spontaneous episodes of atrial fibrillation ( $2.7 \pm 2.1$ shocks per episode; range 1 to 11 ). Shock therapy from the implantable atrial defibrillator terminated $50(93 \%)$ of 54 of these episodes, with $2.4 \pm 1.9$ shocks per atrial fibrillation episode (range 1 to 11 ). A single implantable atrial defibrillator shock terminated and restored sinus rhythm during $12(22 \%)$ of the spontaneous episodes of atrial fibrillation.

Four patients had an episode of atrial fibrillation that did not convert to sinus rhythm after $4.5 \pm 2.4$ shocks (range 3 to 8 ). Two of these four episodes spontaneously converted to sinus rhythm 1 and 2 days later. In the other two patients, the dosage of amiodarone was reduced and sinus rhythm was restored by the implantable atrial defibrillator with two shocks in each patient 2 weeks later. Three patients developed symptomatic bradycardia after shock therapy and required temporary VVI pacing from the device.

\section{Arrhythmia Recurrences}

In the first 3 months after atrial defibrillator implantation, the number of spontaneous episodes of atrial fibrillation per patient $(15 \pm 16)$ was the same as during the subsequent 3 months of follow-up $(12 \pm 16 ; \mathrm{P}=0.2)$. However, the total duration of atrial fibrillation decreased from $126 \pm 172$ hours during the second 3 months compared with $261 \pm 270$ hours during the initial 3 months $(P=0.01)$, after atrial defibrillator implantation (Fig. 2).

There was no significant difference in the number of spontaneous atrial fibrillation episodes between patients with paroxysmal and persistent atrial fibrillation during the initial 3 months ( $22 \pm 18$ episodes per patient vs $9 \pm 13$ episodes per patient; $\mathrm{P}=0.2$ ) and subsequent 3 months $(20 \pm 20$ episodes per patient vs $5 \pm 5$ episodes per patient; $\mathrm{P}=0.08$ ) after atrial defibrillator implantation. During the initial 3 months after device implantation, the total duration of atrial fibrillation for patients with paroxysmal atrial fibrillation was $135 \pm 98$ hours compared with $391 \pm 330$ hours for patients with persistent atrial fibrillation $(\mathrm{P}<0.05)$. During the second 3 months after implantable atrial defibrillator implantation, the total duration of atrial fibrillation was not significantly different between patients with paroxysmal $(68 \pm 120$ hours) and persistent atrial fibrillation (185 \pm 204 hours; $\mathrm{P}=0.2$; Fig. 2). Subgroup analysis demonstrated that the total duration of atrial fi- 


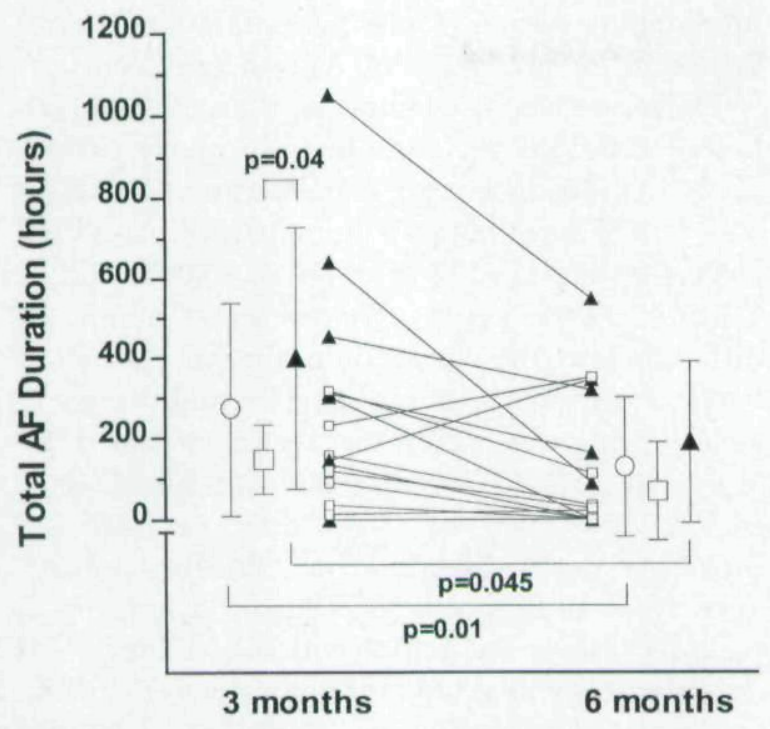

Figure 2. Total duration of atrial fibrillation $(A F)$ for each patient during the first and second 3-month periods after the atrial defibrillator was implanted. Statistically significant $p$ values are shown. Circles represent the mean duration ( \pm $1 S D)$ of $A F$ in all of the patients. Triangles and squares represent the mean $( \pm 1 S D)$ and individual data for patients with persistent and paroxysmal atrial fibrillation, respectively.

brillation did not change significantly among patients with paroxysmal atrial fibrillation $(36 \pm 98$ hours vs $68 \pm 120$ hours; $\mathrm{P}=0.09$ ), whereas patients with persistent atrial fibrillation had a significant reduction in the total duration of atrial fibrillation $(391 \pm 330$ hours vs $185 \pm 204$ hours; $\mathrm{P}<0.05)$. Six months after implantable atrial defibrillator implantation, each patient was in sinus rhythm.

\section{Echocardiographic Results}

At the time of atrial defibrillator implantation, the mean left ventricular ejection fraction was $0.56 \pm 0.08$, and the mean left atrial diameter by echocardiography was $4.4 \pm 0.7 \mathrm{~cm}$. Prior to implantation of the device, patients with persistent atrial fibrillation had a significantly larger left atrial diameter than patients with paroxysmal atrial fibrillation $(4.8 \pm 0.8 \mathrm{~cm}$ vs $4.1 \pm 0.5 \mathrm{~cm}$; $\mathrm{P}=0.03$; Table 2). After 6 months of treatment with the implantable atrial defibrillator, left ventricular ejection fraction did not change significantly $(0.59 \pm 0.05 ; \mathrm{P}=0.08)$; however, there was a significant reduction in left atrial size compared with before device implantation $(4.1 \pm 0.6$ $\mathrm{cm} ; \mathrm{P}=0.02$; Fig. 3). Left atrial size did not change significantly among patients with paroxysmal atrial fibrillation $(4.1 \pm 0.5 \mathrm{~cm}$ vs $4.0 \pm$ $0.4 \mathrm{~cm} ; \mathrm{P}=0.2$ ), whereas patients with persistent atrial fibrillation demonstrated a significant reduction in left atrial size $(4.8 \pm 0.8 \mathrm{~cm}$ vs $4.3 \pm 0.7 \mathrm{~cm} ; \mathrm{P}<0.05$; Fig. 3).

\section{Early Reinitiation of Atrial Fibrillation}

Reinitiation of atrial fibrillation within 1 minute of successful cardioversion of a spontaneous episode of atrial fibrillation occurred after $11(20 \%)$ of 54 successfully treated episodes of atrial fibrillation in 6 of the 12 patients who received treatment for a spontaneous episode of atrial fibrillation. If early reinitiation of atrial fibrillation is considered a clinical failure, then the overall clinical efficacy of the device was $83 \%$. Sinus rhythm was restored after six of these episodes with acute administration of intravenous procainamide in 1 patient, intravenous flecainide in 2 patients, and intravenous sotalol in 3 patients, followed immediately by cardioversion with the device. In the remaining five episodes, 1 patient converted spontaneously to sinus rhythm 20 minutes after intravenous administration of flecainide and 4 patients converted spontaneously to sinus rhythm without further therapy within 48 hours. Implantable atrial defibrillator therapy associated with early reinitiation of atrial fibrillation required $4.0 \pm 3.1$ shocks per atrial

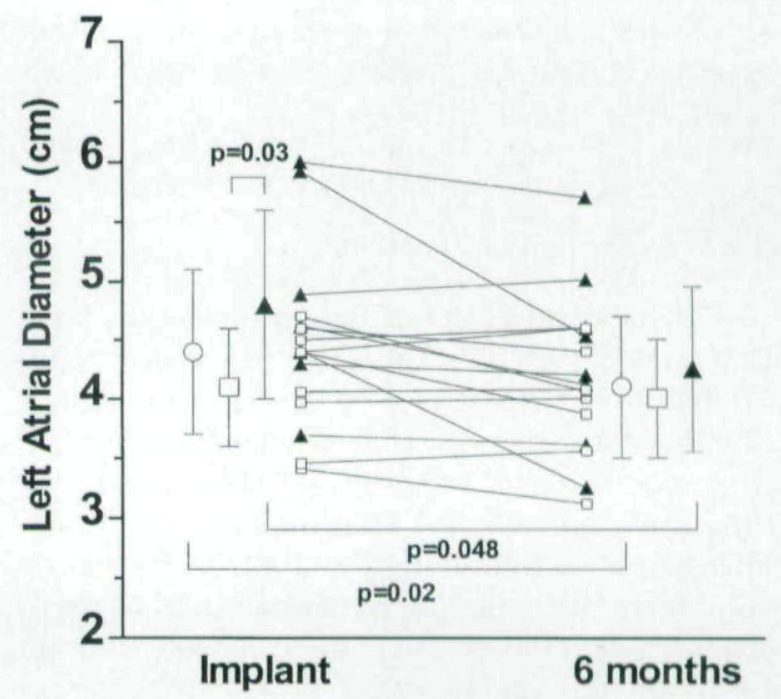

Figure 3. Left atrial diameter determined by echocardiography at the time of implantable atrial defibrillator implantation and 6 months later for each patient. Statistically significant $p$ values are shown. Symbols as in Figure 2. 

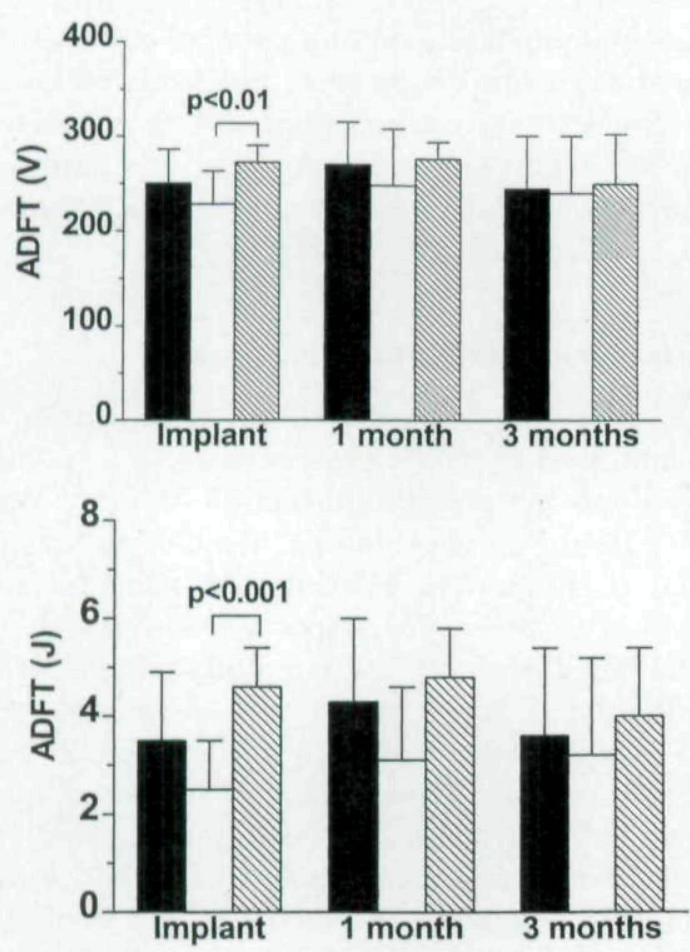

Figure 4. Atrial defibrillation threshold (ADFT) in volts (V) and joules $(J)$ determined during device implantation, and 1 and 3 months later. Solid bars include all patients; open bars include only data from patients with paroxysmal atrial fibrillation; and hatched bars include only data from patients with persistent atrial fibrillation. Statistically significant $p$ values are shown.

fibrillation episode compared with $2.2 \pm 1.5$ shocks per atrial fibrillation episode that was not associated with early reinitiation of atrial fibrillation $(\mathrm{P}=0.02)$.

\section{Atrial Defibrillation Thresholds}

The mean atrial defibrillation thresholds were $250 \pm 36 \mathrm{~V}(3.5 \pm 1.3 \mathrm{~J}), 270 \pm 45 \mathrm{~V}(4.3 \pm 1.0$ $\mathrm{J})$, and $245 \pm 56 \mathrm{~V}(3.6 \pm 1.8 \mathrm{~J})$ at implant, 1 month, and 3 months after device implantation, respectively ( $\mathrm{P}=0.6$; Fig. 4 ). The mean lead impedance was $65 \pm 4 \Omega$ at implant and did not change during follow-up $(\mathrm{P}=0.8)$. There was no significant difference in the initial atrial defibrillation threshold between patients receiving or not receiving amiodarone $(255 \pm 10 \mathrm{~V}$ vs $240 \pm 15$ $\mathrm{V} ; \mathrm{P}=0.5$ ). At implant, three patients with persistent atrial fibrillation had an atrial defibrillation threshold $>260 \mathrm{~V}$. After the administration of intravenous ibutilide in two patients and intravenous sotalol in one patient, an atrial defibrillation threshold $<260 \mathrm{~V}$ was achieved.

During device implantation, the atrial defibrillation threshold was significantly greater in patients with persistent atrial fibrillation ( $272 \pm 18$ $\mathrm{V} ; 4.6 \pm 0.8 \mathrm{~J}$ ) than in patients with paroxysmal atrial fibrillation $(228 \pm 35 \mathrm{~V}, \mathrm{P}<0.01 ; 2.5 \pm$ $1 \mathrm{~J}, \mathrm{P}<0.001$; Fig. 4). There was no significant difference in the atrial defibrillation threshold between patients with paroxysmal and persistent atrial fibrillation during the 1-month ( $248 \pm 60$ $\mathrm{V}$ vs $276 \pm 18 \mathrm{~V} ; \mathrm{P}=0.2)$ and 3 -month $(240 \pm$ $61 \mathrm{~V}$ vs $250 \pm 53 \mathrm{~V} ; \mathrm{P}=0.7)$ atrial defibrillation threshold determination. The shocking impedance was similar between these two groups of patients during the initial and subsequent atrial defibrillation threshold determinations $(\mathrm{P}=0.8)$.

The atrial defibrillation threshold was significantly greater among patients with persistent, as compared with paroxysmal, atrial fibrillation $(\mathrm{P}<0.01$; Table 2). Otherwise, there was no significant correlation between the initial atrial defibrillation threshold and any identifiable clinical characteristic, including age $(P=0.7)$, gen$\operatorname{der}(\mathrm{P}=0.8)$, duration of atrial fibrillation $(\mathrm{P}=$ $0.5)$, left ventricular ejection fraction $(\mathrm{P}=0.3)$, or left atrial size $(\mathrm{P}=0.3)$.

\section{Tolerance of Shocks}

Two (17\%) of 12 patients did not request sedation for implantable atrial defibrillator therapy that was delivered for 17 spontaneous episodes of atrial fibrillation. Four patients tolerated a single atrial defibrillator shock without sedation during six spontaneous episodes of atrial fibrillation, but requested sedation when more than one shock was required. The remaining six patients requested sedation for 26 spontaneous episodes of atrial fibrillation for which atrial defibrillator therapy was delivered. Sedation was achieved with intravenous administration of 2 to $10 \mathrm{mg}$ of midazolam $(5.3 \pm 3.2 \mathrm{mg})$.

\section{Complications}

There were no acute complications associated with implantation of the atrial defibrillator. One patient developed subclavian vein thrombosis 2 weeks after the device was implanted and was treated with warfarin. Ventricular proarrhythmia was not observed during the study. No thromboembolic events were noted during the study. 


\section{Discussion}

\section{Main Findings}

The major finding of this study is that maintenance of sinus rhythm with repeated cardioversion with an implantable atrial defibrillator in combination with antiarrhythmic drugs may favorably influence the natural history of atrial fibrillation by reducing the total duration of atrial fibrillation and reducing left atrial size in patients with persistent atrial fibrillation.

\section{Mechanism}

Although the technical feasibility, safety, and efficacy of the implantable atrial defibrillator has been reported, ${ }^{3-5}$ the data contained herein are the first to suggest that aggressive maintenance of sinus rhythm with the implantable atrial defibrillator may alter the progressive nature of atrial fibrillation, may reverse at least some portion of the associated atrial myopathy, and support the notion that sinus rhythm predisposes to sinus rhythm.

Previous studies in animals and humans suggest that rapid cardioversion of atrial fibrillation may prevent the electrical remodeling that occurs with atrial fibrillation, that paroxysmal and persistent atrial fibrillation lead to progressive atrial enlargement, and that left atrial size correlates with the duration of atrial fibrillation. ${ }^{1,2,6-9}$ This suggests that enlarged atria are more likely to occur in patients with persistent atrial fibrillation and, therefore, would be more likely to demonstrate reversal of this process with maintenance of sinus rhythm. Additionally, atrial enlargement is associated with a greater risk of arrhythmia recurrence, as well as thromboembolic complications. ${ }^{10-12}$ The results of the present study imply that restoration and maintenance of sinus rhythm by repeated cardioversion may reverse the process of left atrial enlargement by reversing the mechanical remodeling process associated with atrial fibrillation. The reduction in left atrial size and total duration of atrial fibrillation was more prominent in patients with persistent atrial fibrillation than in those with paroxysmal atrial fibrillation. The strength of these data is limited by the relatively small sample size, only two echocardiographic measurements of left atrial size, and a clinical follow-up period of only 6 months. However, additional investigation is required to determine if maintenance of sinus rhythm and a reduction in left atrial size will reduce the risk of the thromboembolic complications associated with atrial fibrillation.

\section{Early Reinitiation of Atrial Fibrillation}

Early reinitiation of atrial fibrillation occurs after successful internal defibrillation, with or without an implantable atrial defibrillator, in $13 \%$ to $36 \%$ of patients. ${ }^{4.13-15}$ A $20 \%$ incidence was noted in the present study. Atrial fibrillation is associated with atrial electrical remodeling in animals and humans and is the mechanism whereby atrial fibrillation provokes atrial fibrillation. ${ }^{1,2}$ It is reasonable to assume that electrical remodeling also is responsible for early reinitation of atrial fibrillation after a successful cardioversion. In the present study, early reinitiation of atrial fibrillation was associated with an increased number of shocks per atrial fibrillation episode and a reduced overall clinical efficacy of the implantable atrial defibrillator from $93 \%$ to $83 \%$. In the present study and in previous reports, intravenous administration of a Class I or III antiarrhythmic agent appeared to suppress the early reinitiation of atrial fibrillation in some patients. ${ }^{13-15}$

\section{Concomitant Drug Therapy}

Although the implantable atrial defibrillator effectively restored sinus rhythm, the majority of patients still required chronic adjunctive antiarrhythmic therapy to reduce the frequency of atrial fibrillation or to prevent early recurrences of atrial fibrillation. Antiarrhythmic agents also may influence the efficacy of cardioversion with the implantable atrial defibrillator. In the present study, there was no significant difference in the initial atrial defibrillation threshold between patients undergoing concomitant treatment with or without amiodarone. However, in two patients who failed cardioversion, a reduction of the amiodarone dosage was associated with a reduction of the atrial defibrillation requirement. In previous studies, amiodarone had a variable effect on the atrial defibrillation threshold, and intravenous sotalol and ibutilide were associated with a lower atrial defibrillation threshold. ${ }^{16-20}$

\section{Patient Acceptance of Implantable Atrial Defibrillator Therapy}

For the implantable atrial defibrillator to be a viable clinical tool, the discomfort associated 
with device shocks must be manageable. In the present study, only $20 \%$ of patients underwent atrial defibrillator shocks without sedation. The discomfort associated with the shocks may be related to the number of delivered shocks and not to the intensity of the individual shocks. ${ }^{21}$ Therefore, to improve patient acceptance of the implantable atrial defibrillator, the first shock energy should be associated with a high probability of successful defibrillation. Successful defibrillation is a function of many factors, including electrode design and position, shock waveform and polarity, concomitant antiarrhythmic drug therapy, and clinical factors. ${ }^{19,21-26}$ Maximizing the defibrillation system may increase the number of patients who do not require sedation. Finally, the use of an oral sedative with rapid absorption and a short duration of action prior to implantable atrial defibrillator therapy may increase patient acceptance. ${ }^{22}$

\section{Limitations}

The major limitation of this study is that, depending on when the atrial fibrillation episode occurred relative to the sensing cycle, some episodes of atrial fibrillation may not have been sensed while multiple episodes may have been defined as a single episode. Due to this device limitation, the duration and number of episodes may have been overcounted or undercounted. However, overcounting and undercounting most likely occurred randomly throughout the study, thereby reducing or eliminating the importance of this limitation. The second limitation of this study is that the serial echocardiograms and atrial defibrillation thresholds were not performed at the same points in time. This limits the ability to correlate the findings from these two tests. Finally, the natural history of persistent and paroxysmal atrial fibrillation is not well defined.

\section{Clinical Implications}

The results of the present study suggest that repeated cardioversion with an implantable atrial defibrillator might reverse the process of mechanical atrial remodeling in patients with persistent atrial fibrillation. The use of the implantable atrial defibrillator in the patient activated or automatic mode may intensify this effect by providing prompter therapy for atrial fibrillation. The implantable atrial defibrillator may have a greater effect on the natural history of atrial fibrillation in patients with persistent atrial fibrillation as opposed to patients with paroxysmal atrial fibrillation.

\section{References}

1. Wijffels MC, Kirchhof CJ, Dorland R, et al: Atrial fibrillation begets atrial fibrillation: A study in awake chronically instrumented goats. Circulation 1995;92: 1954-1968.

2. Daoud EG, Bogun F, Goyal R, et al: Effect of atrial fibrillation on atrial refractoriness in humans. Circulation 1996;94:1600-1606.

3. Lau C-P, Tse H-F, Lok NS, et al: Initial clinical experience with an implantable human atrial defibrillator. PACE 1997;20:220-225.

4. Wellens H, Lau C-P, Lüderitz B, et al: Atrioverter, an implantable device for the treatment of atrial fibrillation. Circulation 1998;98:1651-1656.

5. Tse H-F, Lau C-P, Sra JS, et al: Atrial fibrillation detection and R-wave synchronization by Metrix implantable atrial defibrillator: Implications for long term efficacy and safety. Circulation 1999;99:1446-1451.

6. Petersen P, Kastrup J, Brinch K, et al: Relation between left atrial size and duration of atrial fibrillation. Am J Cardiol 1987;60:382-384.

7. Sanfilippo AJ, Abascal VM, Sheenan M, et al: Atrial enlargement as a consequence of atrial fibrillation. Circulation 1990;82:792-797.

8. Morillo CA, Klein GJ, Jones DJ, et al: Chronic rapid atrial pacing: structural functional, and electrophyiological characteristics of a new model of sustained atrial fibrillation. Circulation 1995;91:1588-1595.

9. Ausma J, Wijffels M, Thone F, et al: Structural changes of atrial myocardium due to sustained atrial fibrillation in the goat. Circulation 1997;96:3157-3163.

10. Henry WL, Morganroth J, Pearlman AS, et al: Relation between echocardiographically determined left atrial size and atrial fibrillation. Circulation 1976;53:273279.

11. Brodsky MA, Allen BJ, Capparelli EV, et al: Factors determining maintenance of sinus rhythm after chronic atrial fibrillation with left atrial dilatation. Am J Cardiol 1989;63:1065-1068.

12. The Stroke Prevention in Atrial Fibrillation Investigators: Predictors of thromboembolism in atrial fibrillation: II. Echocardiographic features of patients at risk. Ann Intern Med 1992;116:6-12.

13. Tse H-F, Lau C-P, Lok NS: Early recurrence of atrial fibrillation after successful defibrillation in patients with chronic atrial fibrillation. (Abstract) PACE 1997; 20:2305.

14. Timmermans C, Rodriguez LM, Smeets JLRM, et al: Immediate reinitiation of atrial fibrillation following internal atrial defibrillation. J Cardiovasc Electrophysiol 1998;9:122-128.

15. Sra J, Biehl M, Blanck Z, et al: Spontaneous reinitiation 
of atrial fibrillation following transvenous atrial defibrillation. PACE 1998;21:1105-1110.

16. Sagristà-Sauleda J, Permanyer-Miralda G, Soler-Soler $\mathrm{J}$ : Electrical cardioversion after amiodarone administration. Am Heart J 1992;123:1536-1542.

17. Ligorit A, Casasnovas Lenguas JA, Gonzales Carretero M: The influence of amiodarone on the response to cardioversion in patients with arrhythmias caused by atrial fibrillation. Med Clin 1983;81:618-620.

18. Mende M, Kluge P, Walter T, et al: Changes in internal atrial defibrillation threshold under treatment with amiodarone in patients with chronic atrial fibrillation. (Abstract) Circulation 1998;98:I102.

19. Lau C-P, Lok NS: A comparison of transvenous atrial defibrillation of acute and chronic atrial fibrillation and the effect of intravenous sotalol on human atrial defibrillation threshold. PACE 1997;20:1-11.

20. Oral H, Souza JJ, Flemming M, et al: Effect of ibutilide on atrial defibrillation energy requirement. (Abstract) J Am Coll Cardiol 1999;33:132A.

21. Lok NS, Lau C-P, Tse H-F, et al: Clinical shock tolerability and effect of different right atrial electrode locations on efficacy of low energy human transvenous atrial defibrillation using an implantable lead system. J Am Coll Cardiol 1997;30:1324-1330.

22. Ayers GM: How can atrial defibrillation be made more tolerable? In Murgatroyd FD, Camm AJ, eds: Nonpharmacological Management of Atrial Fibrillation. Futura Publishing Co., Armonk, NY, 1997, pp. 474-487.

23. Tomassoni G, Newby KH, Kearney MM, et al: Testing different biphasic waveforms and capacitances: Effect on atrial defibrillation threshold and pain perception. J Am Coll Cardiol 1996;28:695-699.

24. Cooper RAS, Johnson EE, Wharton JM: Internal atrial defibrillation in humans: Improved efficacy of biphasic waveforms and the importance of phase duration. Circulation 1997;95:1487-1496.

25. Harbinson MT, Allen JD, Imam Z, et al: Rounded biphasic waveform reduces energy requirements for transvenous catheter cardioversion of atrial fibrillation and flutter. PACE 1997;20:226-229.

26. Cooper RAS, Plumb VJ, Epstein AE, et al: Marked reduction in internal atrial defibrillation threshold with dual-current pathways and sequential shocks in human. Circulation 1998;97:2527-2535. 
This document is a scanned copy of a printed document. No warranty is given about the accuracy of the copy. Users should refer to the original published version of the material. 